\title{
Estimation of sodium and chloride storage in critically ill patients: a balance study
}

\author{
Lara Hessels ${ }^{1 *} \mathbb{D}$, Annemieke Oude Lansink-Hartgring ${ }^{1}$, Miriam Zeillemaker-Hoekstra ${ }^{1,2}$ and Maarten W. Nijsten ${ }^{1}$
}

\begin{abstract}
Background: Nonosmotic sodium storage has been reported in animals, healthy individuals and patients with hypertension, hyperaldosteronism and end-stage kidney disease. Sodium storage has not been studied in ICU patients, who frequently receive large amounts of sodium chloride-containing fluids. The objective of our study was to estimate sodium that cannot be accounted for by balance studies in critically ill patients. Chloride was also studied. We used multiple scenarios and assumptions for estimating sodium and chloride balances.

Methods: We retrospectively analyzed patients admitted to the ICU after cardiothoracic surgery with complete fluid, sodium and chloride balance data for the first 4 days of ICU treatment. Balances were obtained from meticulously recorded data on intake and output. Missing extracellular osmotically active sodium (MES) was calculated by subtracting the expected change in plasma sodium from the observed change in plasma sodium derived from balance data. The same method was used to calculate missing chloride (MEC). To address considerable uncertainties on the estimated extracellular volume (ECV) and perspiration rate, various scenarios were used in which the size of the ECV and perspiration were varied.

Results: A total of 38 patients with 152 consecutive ICU days were analyzed. In our default scenario, we could not account for $296 \pm 35 \mathrm{mmol}$ of MES in the first four ICU days. The range of observed MES in the five scenarios varied from $111 \pm 27$ to $566 \pm 41 \mathrm{mmol}(P<0.001)$. A cumulative value of $243 \pm 46 \mathrm{mmol}$ was calculated for MEC in the default scenario. The range of cumulative MEC was between $62 \pm 27$ and $471 \pm 56 \mathrm{mmol}(P=0.001$ and $P=0.003)$. MES minus MEC varied from $1 \pm 51$ to $123 \pm 33 \mathrm{mmol}$ in the five scenarios.

Conclusions: Our study suggests considerable disappearance of osmotically active sodium in critically ill patients and is the first to also suggest rather similar disappearance of chloride from the extracellular space. Various scenarios for insensible water loss and estimated size for the ECV resulted in considerable MES and MEC, although these estimates showed a large variation. The mechanisms and the tissue compartments responsible for this phenomenon require further investigation.
\end{abstract}

Keywords: Sodium, Chloride, Intensive care unit, Intracellular volume, Extracellular volume

\section{Background}

When long-term balance studies in humans demonstrated that sodium could accumulate without weight gain or hypernatremia, this challenged the generally accepted model on sodium homeostasis [1]. This model states that changes in sodium homeostasis can primarily be explained by a two-compartment model with an

\footnotetext{
*Correspondence: lara.hessels@gmail.com

${ }^{1}$ Department of Critical Care, University of Groningen, University Medical Center Groningen, Hanzeplein 1, 9700 RB Groningen, The Netherlands

Full list of author information is available at the end of the article
}

intracellular (ICV) and extracellular volume (ECV), where key ions are completely dissolved-i.e., osmotically active. An extra compartment that stores sodium nonosmotically without causing an expansion of the ECV has been proposed by Titze et al. [2]. In both animal and human studies, they found that sodium is stored nonosmotically in the skin $[2,3]$. Nonosmotic sodium storage is presumably facilitated by large strongly negatively charged polymers such as glycosaminoglycans $[4$, 5]. The accumulation of chloride in the skin has been 
suggested in animal models [6,7], but has not been as extensively studied as sodium storage.

Patients admitted to the intensive care unit (ICU) typically receive large amounts of sodium and chloride during their ICU treatment [8]. Both hypernatremia and hyperchloremia are a frequent complication in critically ill patients and are associated with adverse outcome [9-12]. The infusion of high amounts of chloride is also recognized as cause of hyperchloremic acidosis [11, 12]. Improved understanding of sodium chloride homeostasis in this patient group is therefore of utmost importance. To our knowledge, no studies have tried to measure missing sodium as evidence of stored sodium in ICU patients. Likewise, a potentially similar phenomenon for chloride has not been studied yet.

The objective of our study was therefore to estimate sodium and chloride that might 'disappear' in balance studies in ICU patients. Since random and systematic errors as well as different assumptions on the size of the ECV and perspiration strongly affect the calculated sodium or chloride deficit, five scenarios were tested in which the assumed sizes of the ECV or perspiration were varied.

\section{Methods}

\section{Study design}

This observational retrospective balance study involved all patients of $\geq 18$ years admitted to a tertiary cardiothoracic ICU from October 2010 until December 2014 with a minimal ICU length of stay of 4 days.

\section{Data collection}

Data that were collected and analyzed included basic demographics, reason of admission, acute physiology and chronic health evaluation (APACHE-IV) score for disease severity, acute kidney injury according to the KDIGO AKI criteria in the first 7 days and in-hospital mortality [13]. Fluid, sodium and chloride balances were derived from meticulously recorded input records (including enteral and parenteral feeding and administered fluids, including creep fluids such as solvent solutions) and output records, including daily $24-\mathrm{h}$ urine collections. Our ICU did not have a full electronic patient database management system during the study period. Therefore, all data were derived from nursing and medical charts. All electrolyte concentrations, determined in blood or 24-h urine, were collected.

\section{Estimation of missing extracellular osmotically active sodium (MES) and chloride (MEC)}

The most important components to determine electrolyte balances are detailed records of fluids, administered to or lost by the patient, including 24-h urine analyses.
The detailed calculations used for determining water, sodium and chloride balances, including the estimation for (in)sensible perspiration, have been described earlier and are specified in detail in Additional file 1: Tables S1S3 [8]. Insensible perspiration was calculated as:

Insensible perspiration $=10 \mathrm{~mL} / \mathrm{kg} /$ day $+2.5 \mathrm{~mL} /$ $\mathrm{kg} /$ day per degree centigrade above $37^{\circ} \mathrm{C}$ (max body weight in equation $100 \mathrm{~kg})(\times 0.6$ if intubated $)(\times 0.5$ on admission day) [14].

For insensible perspiration, core temperature measured via the bladder catheter was used.

To estimate MES for each ICU patient, we compared the observed changes in estimated extracellular $\Delta \mathrm{Na}_{\mathrm{obs}}$ with the expected change $\left(\Delta \mathrm{Na}_{\text {exp }}\right)$.

Of every ICU calender day, last measured plasma sodium was compared with the last measured plasma sodium of the previous day. For electrolyte measurements, the direct ion-selective method was used. For the patients studied, we defined the ECV at $40 \%$ in our default model, since surgical patients receive a considerable fluid load perioperatively [15]. We corrected for different sizes of the ECV at the beginning of the day versus the end of day, due to infused fluids.

Only $E C V_{\text {first }}$ that was calculated for admission day used measured body weight:

$$
\mathrm{ECV}_{\text {first }}=0.4 \times \text { body weight }(\mathrm{kg}) .
$$

The extracellular volume at the end of the day (i.e., 23:59) was defined as:

$$
\mathrm{ECV}_{23: 59}=\mathrm{ECV}_{\text {previous }}+\text { fluid balance }(\mathrm{L}),
$$

where $\mathrm{ECV}_{\text {previous }}$ is the ECV from $24 \mathrm{~h}$ earlier, or in the case it concerns the end of the first ICU day it relates to $\mathrm{ECV}_{\text {first }}$.

The extracellular volume at the beginning of the next day (i.e., 00:00) was defined as:

$$
\mathrm{ECV}_{00: 00}=\mathrm{ECV}_{\text {last of the previous day }}(\mathrm{L}) \text {. }
$$

The expected change in total amount of sodium in the ECV over a calender day was defined as:

$$
\begin{aligned}
\Delta \mathrm{Na}_{\text {exp }}^{+}= & {\left[\mathrm{Na}^{+}\right]_{\text {last }} \times \mathrm{ECV}_{\text {last }}-\left[\mathrm{Na}^{+}\right]_{\text {previous }} } \\
& \times \mathrm{ECV}_{\text {previous }}(\mathrm{mmol}) .
\end{aligned}
$$

The observed change in total extracellular sodium on the basis of administrated and excreted sodium was thereafter defined as:

$$
\Delta \mathrm{Na}_{\text {obs }}^{+}=\text {sodium balance }=\mathrm{Na}_{\text {in }}-\mathrm{Na}_{\text {out }}(\mathrm{mmol}) .
$$

The missing extracellular osmotically active sodium that apparently 'disappeared' from the ECV was defined as: 
MES $=\Delta \mathrm{Na}_{\mathrm{obs}}-\Delta \mathrm{Na}_{\mathrm{exp}}(\mathrm{mmol})$

For chloride, the same method as described above was used to calculate MEC, where instead of sodium, chloride should be read.

As a sensitivity analysis to test the robustness of our results, we tested $2 \times 2$ additional more extreme scenarios with respect to our assumptions on the ECV and perspiration. Where the default model assumed an ECV of $40 \%$ of the body weight and an insensible perspiration of $10 \mathrm{~mL} / \mathrm{kg} /$ day, we tested both an extracellular compartment of $20 \%$ of body weight [16] and $60 \%$ of body weight [17]. In order to encapsulate the wide uncertainty in estimating actual perspiration, we also tested both lower and upper published extremes in perspiration rate of $5 \mathrm{~mL} /$ $\mathrm{kg} /$ day plus $2.5 \mathrm{~mL} / \mathrm{kg} /$ day per degree centigrade above $37{ }^{\circ} \mathrm{C}$ versus and a perspiration rate of $20 \mathrm{~mL} / \mathrm{kg} /$ day plus $2.5 \mathrm{~mL} / \mathrm{kg} /$ day per degree centigrade above $37^{\circ} \mathrm{C}$.

To assess the differences in ECV between males and females, we performed a sub-analysis. In this analysis, an ECV of $40 \%$ of the body weight was assumed for males and an ECV of $30 \%$ was assumed for females.

\section{Statistical analyses}

Means are given $\pm \mathrm{SE}$, medians with interquartile range, unless otherwise indicated. MES and MEC were compared with a Student's $t$ test. A two-sided $P<0.05$ was considered significant. Cumulative calculations took account of increases in cumulative errors with the Pythagorean theory of error propagation. Balance calculations and statistical analysis were performed with SPSS 23.0 (IBM, Chicago, IL).

\section{Results}

A total of 38 patients with 152 consecutive ICU days were included. Their baseline characteristics are given in Table 1.

The included patients received large amounts of fluids $(13.6 \pm 0.6 \mathrm{~L})$, sodium $(1441 \pm 75 \mathrm{mmol})$ and chloride $(1377 \pm 76 \mathrm{mmol})$ in the 4-day period, resulting in a cumulative fluid balance of $3.9 \pm 0.6 \mathrm{~L}$, a sodium balance of $822 \pm 76 \mathrm{mmol}$ and a chloride balance of $556 \pm 82 \mathrm{mmol}$. Both the mean plasma sodium and chloride concentrations did not significantly change during the first four ICU days (Table 2).

\section{Missing extracellular osmotically active sodium and chloride}

Based on our calculations, for sodium a MES of $74 \pm 15 \mathrm{mmol}$ per day was observed. This resulted in a cumulative MES of $296 \pm 35 \mathrm{mmol}$ during four ICU days (Fig. 1). For chloride, a MEC of $61 \pm 23 \mathrm{mmol}$ per day was
Table 1 Patients characteristics

\begin{tabular}{lc}
\hline & $n=38$ \\
\hline Age (years) & $66(13)$ \\
Sex, male & $28(74 \%)$ \\
Reason of admission & \\
Cardiothoracic surgery & $31(82 \%)$ \\
Trauma & $1(3 \%)$ \\
Vascular surgery & $1(3 \%)$ \\
Miscellaneous & $5(13 \%)$ \\
LOS ICU (days) & $7.4(4.8-13.7)$ \\
Patients on diuretics & $25(66 \%)$ \\
APACHE-IV & $60(44-71)$ \\
Hospital mortality & $4(11 \%)$ \\
AKI & $11(29 \%)$ \\
Stage 1 & $6(55 \%)$ \\
Stage 2 & $3(27 \%)$ \\
Stage 3 & $2(18 \%)$ \\
\hline
\end{tabular}

Data are depicted as mean (SD), $n$ (\%) or median (interquartile range) as appropriate

APACHE Acute Physiology and Chronic Health Evaluation

seen with a cumulative MEC of $243 \pm 46 \mathrm{mmol}$ over the first four ICU days (Fig. 1).

We also calculated the difference between MES and MEC. The cumulative difference was $56 \pm 40 \mathrm{mmol}$ over the first four ICU days.

\section{Scenarios}

In the four scenarios in addition to the default scenario, we changed the assumed ECV and assumed perspiration and assessed their impact on MES and MEC (Figs. 2 and 3).

When perspiration was increased to $20 \mathrm{~mL} / \mathrm{kg} /$ day, MES doubled for both the $20 \%$ and $60 \%$ ECV scenario $(551 \pm 35 \mathrm{mmol}$ and $566 \pm 41 \mathrm{mmol}$, respectively, both $P<0.001$, Fig. 2a). After decreasing perspiration to $5 \mathrm{~mL} / \mathrm{kg} /$ day, in both the ECV of $20 \%$ and $60 \%$ scenario, the amount of sodium we could not account for decreased more than 2.5 times the initial calculated MES $(111 \pm 27 \mathrm{mmol}$ and $126 \pm 31 \mathrm{mmol}$, respectively, both $P<0.001)$.

When these four scenarios were repeated for the calculations of MEC, similar results were obtained. When perspiration was increased to $20 \mathrm{~mL} / \mathrm{kg} /$ day, for both the $20 \%$ and $60 \%$ ECV scenario we observed a similar increase in MEC from $243 \pm 46 \mathrm{mmol}$ to $414 \pm 39 \mathrm{mmol}$ $(P=0.006)$ to and $471 \pm 56 \mathrm{mmol}(P=0.003$, Fig. $2 \mathrm{~b})$. After decreasing perspiration to $5 \mathrm{~mL} / \mathrm{kg} /$ day, MEC decreased. A MEC of $62 \pm 27 \mathrm{mmol}$ was observed when ECV was set at $20 \%$ in the low perspiration scenario $(P=0.001)$. However, when ECV was defined as $60 \%$, 
Table 2 Cumulative data on fluid and electrolyte administration

\begin{tabular}{|c|c|c|c|c|c|}
\hline & Day 1 & Day 2 & Day 3 & Day 4 & $P^{*}$ \\
\hline \multicolumn{6}{|l|}{ Intake } \\
\hline Fluid (L) & $3.6 \pm 0.4$ & $7.9 \pm 0.5$ & $11.0 \pm 0.5$ & $13.6 \pm 0.6$ & \\
\hline Sodium (mmol) & $460 \pm 52$ & $935 \pm 67$ & $1235 \pm 72$ & $1441 \pm 75$ & \\
\hline Chloride $^{\mathrm{a}}(\mathrm{mmol})$ & $420 \pm 53$ & $872 \pm 68$ & $1162 \pm 79$ & $1377 \pm 76$ & \\
\hline \multicolumn{6}{|l|}{ Output } \\
\hline Fluid (L) & $1.6 \pm 0.1$ & $3.9 \pm 0.2$ & $6.5 \pm 0.3$ & $8.9 \pm 0.3$ & \\
\hline Sodium (mmol) & $139 \pm 14$ & $293 \pm 23$ & $472 \pm 30$ & $626 \pm 35$ & \\
\hline Chloride $^{\mathrm{a}}(\mathrm{mmol})$ & $117 \pm 17$ & $255 \pm 28$ & $418 \pm 43$ & $574 \pm 47$ & \\
\hline \multicolumn{6}{|l|}{ Balance } \\
\hline Fluid (L) & $1.9 \pm 0.3$ & $3.7 \pm 0.5$ & $4.0 \pm 0.5$ & $3.9 \pm 0.6$ & \\
\hline Sodium (mmol) & $321 \pm 47$ & $642 \pm 62$ & $769 \pm 72$ & $822 \pm 76$ & \\
\hline Chloride $^{\mathrm{a}}(\mathrm{mmol})$ & $274 \pm 51$ & $498 \pm 66$ & $535 \pm 82$ & $556 \pm 82$ & \\
\hline Plasma sodium (mmol/L) & $137.1 \pm 0.5$ & $136.6 \pm 0.5$ & $136.2 \pm 0.6$ & $136.9 \pm 0.5$ & 0.741 \\
\hline Plasma chloride (mmol/L) & $109.8 \pm 0.9$ & $109.3 \pm 0.8$ & $108.2 \pm 0.9$ & $108.0 \pm 0.9$ & 0.107 \\
\hline
\end{tabular}

Data are depicted as mean \pm SE

* Difference between day 1 and day 4

a Chloride data were available for 27, 27, 24 and 28 patients, respectively, on day 1 to day 4

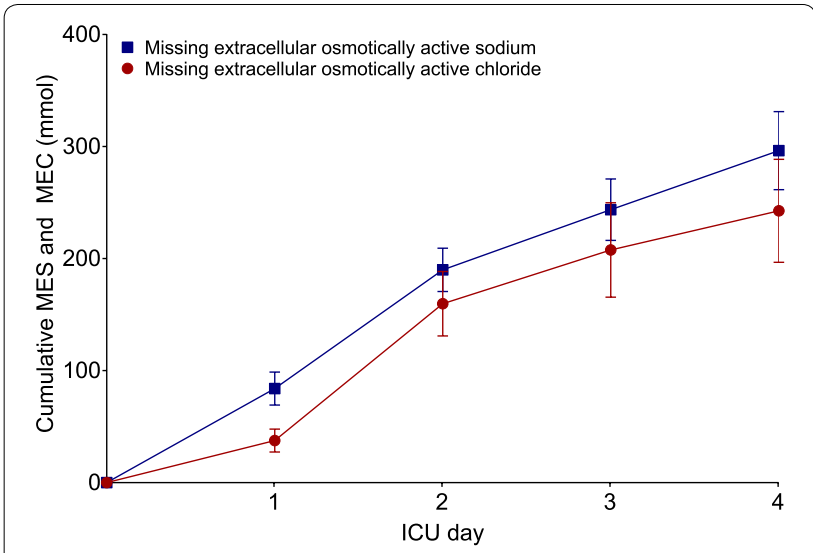

Fig. 1 Time course of estimated cumulative MES and MEC for the first four ICU days. Values are depicted as mean \pm SE. The first values reflect levels at ICU admission, when storage was assumed defined as zero. The values at the subsequent time points reflect levels at the end (i.e., midnight) of each ICU day. As can be seen under normal and stable circulating electrolyte levels (Table 2), a significant amount of sodium (MES) and chloride (MEC) 'disappears' from the balances over the first four ICU days

MEC did not significantly change $(243 \pm 46 \mathrm{mmol}$ vs. $119 \pm 55$ mmol, respectively, $P=0.09$ ).

For all five depicted scenarios, the difference between MES and MEC was also calculated (Fig. 3) to identify potential structural differences between sodium and chloride disappearance. These differences varied from $1 \pm 51$ to $123 \pm 33 \mathrm{mmol}$, indicating that MES and MEC were of the same order of magnitude.
The sub-analysis to assess sexual differences in ECV is found in Additional file 1: Fig. S1.

\section{Discussion}

This is the first balance study that aimed to estimate missing extracellular sodium (MES) in ICU patients and missing extracellular chloride (MEC) in any patient group. Although we found considerable variations in estimated MES and MEC according to the various scenarios, the results suggest a considerable MES and a somewhat lower MEC (Fig. 3).

To calculate MES and MEC, we used one default and four more extreme scenarios, which we believe cover the scope of published sizes of the ECV and rates of perspiration. An ECV of $20 \%$ of body weight is a conservative choice in patients arriving at the ICU after major surgery [16], while $60 \%$ is an extreme estimate [17]. Regarding perspiration, defining the extremes was more difficult, but nearly all sources assume a perspiration $\geq 400 \mathrm{ml} /$ day for both the skin and the respiratory tract without fever [14]. Our estimate of $5 \mathrm{~mL} / \mathrm{kg} /$ day probably is thus the lower limit, while $20 \mathrm{~mL} / \mathrm{kg} /$ day is a large estimate. We believe that the true value of both MES and MEC should be somewhere in between the four more extreme scenarios as depicted in Fig. 3. MES and MEC were mainly influenced by perspiration and MEC also somewhat by the ECV. This underscores that both the size of the ECV and insensible perspiration are important determinants in the estimated size of MES and MEC. In sex-specific models (Additional file 1: Fig. S1), males showed slightly higher MES and MEC compared with females. 

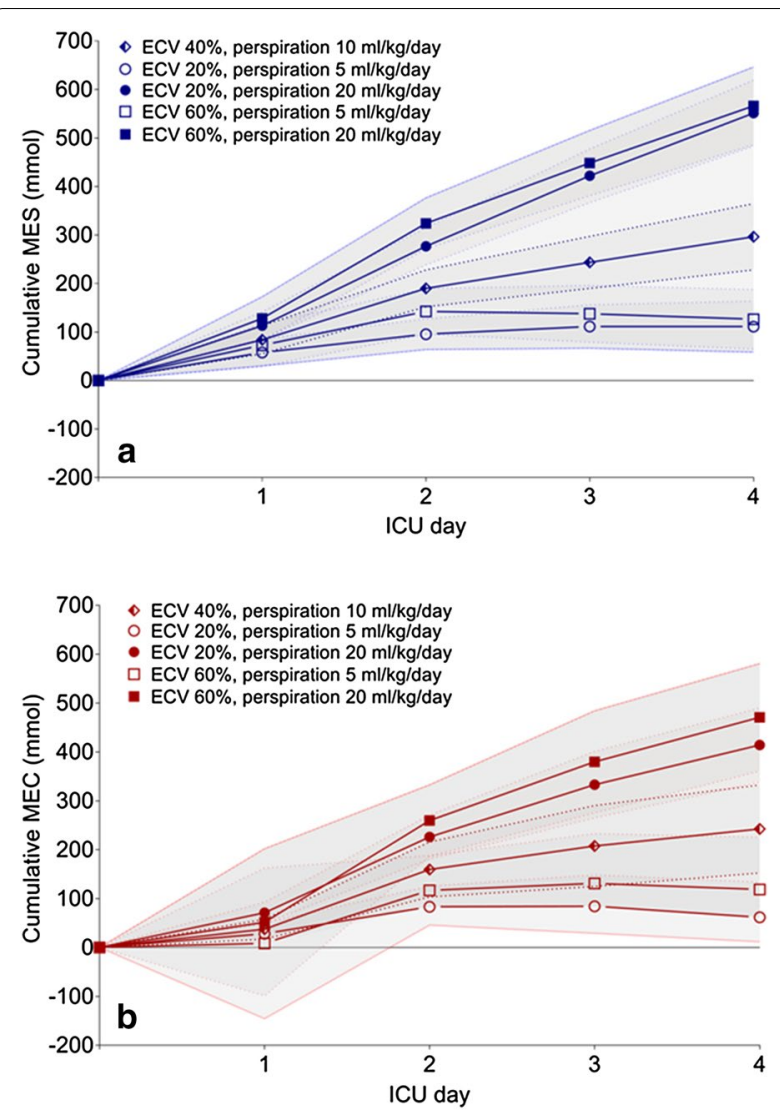

Fig. 2 Scenarios for both estimated cumulative MES and MEC. Values are depicted as mean $\pm 95 \% \mathrm{Cl}$. The $95 \% \mathrm{Cl}$ is represented by the dotted lines. The first values reflect levels at ICU admission, when storage was assumed to be zero. In all scenarios, there were considerable MES and MEC after 4 days of ICU admission. a With stable sodium levels, MES is mostly influenced by altering the insensible perspiration. $\mathbf{b}$ MEC showed a similar pattern as MES, but was slightly more affected by the changes in the extracellular compartment than MES

More sodium and chloride disappeared from the balances during the first two days of ICU admission than in the subsequent days (Fig. 1). Resuscitation fluids, often high in sodium and chloride content, are frequently administered during surgery and in the early postoperative period. Whereas the recommended limits for dietary sodium intake are $2.3 \mathrm{~g} /$ day [18], our patients received an average of $8.3 \mathrm{~g}$ (i.e., $360 \mathrm{mmol}$ ) sodium per day, with positive sodium balances but stable sodium concentrations. This resulted in a MES of $296 \mathrm{mmol}$ after four ICU days. When this MES is expressed in terms of $\mathrm{NaCl} 0.9 \%$ infusion, $1.9 \mathrm{~L}$ of this fluids sodium went missing in our patients.

Nonosmotic sodium storage has been studied in several non-critically ill patient groups. In healthy individuals, it has recently been observed that half of an acute intravenous hypertonic saline load of $201 \mathrm{mmol}$ appears to be briefly stored nonosmotically [19], possibly in interaction with the endothelial glycocalyx. Sodium storage has been reported to increase with advancing age, to be greater in men and patients with hypertension, hyperaldosteronism, end-stage kidney disease and infection [20-22]. Tissue sodium levels are variable and may be altered by dialysis and diuretic treatment $[23,24]$. However, the precise clinical significance of nonosmotic sodium storage has not been defined yet. The existence of nonosmotic sodium storage has not been examined in critically ill patients. Nonosmotic sodium storage could also be relevant in ICU-acquired hypernatremia (IAH) [25] and could explain the relatively long duration of IAH once it develops, although sodium balances were not performed in this study. It is believed that the electrical binding capacity of various tissues for sodium is altered during inflammation [26], which may interact with the development of IAH in critically ill patients. Irrespective of a potential relation between IAH and sodium storage, a strategy in which infusion fluids with lower sodium chloride content are used to reduce IAH is probably desirable [27]. We reported earlier [10] that changes in bulk intravenous fluid constitution paralleled changes in the incidence of ICU-acquired hypernatremia. Recently, it was elegantly shown that maintenance fluid therapy constitutes a higher sodium, chloride and water burden than acute resuscitation fluid administration [28].

With regard to chloride, which also disappeared in our balance calculations, both sodium and chloride storage may affect changes in blood pressure $[6,29]$.

As we cannot explain MES and MEC by the conventional two-compartment model where sodium is extracellular and potassium intracellular, a specific storage compartment may be the buffer of these sodium and chloride loads. The key alternative to nonosmotic storage is loss of sodium and chloride to the ICV. This effect has been demonstrated by healthy persons who sustained muscular injury [30]. Critical illness is often accompanied with critical illness myopathy, and loss of sodium and chloride to the ICV might then also be conceivable [31]. As we reported in an earlier study [8], our patients displayed a negative potassium balance of $101 \mathrm{mmol}$, which is another argument for possible intracellular uptake of sodium in exchange for potassium release. Moreover, we also observed a negative electrolyte-free water (EFW) balance in these patients. Together, this suggests that no ICV expansion occurred [8]. Therefore, we assumed that all fluids administered (including EFW) remained in the ECV. However, if part of the EFW would enter the ICV, this would result in lower increases and thus even higher MES and MEC estimates.

The presence of nonosmotic storage could be verified through direct tissue analysis or via specialized MRI 


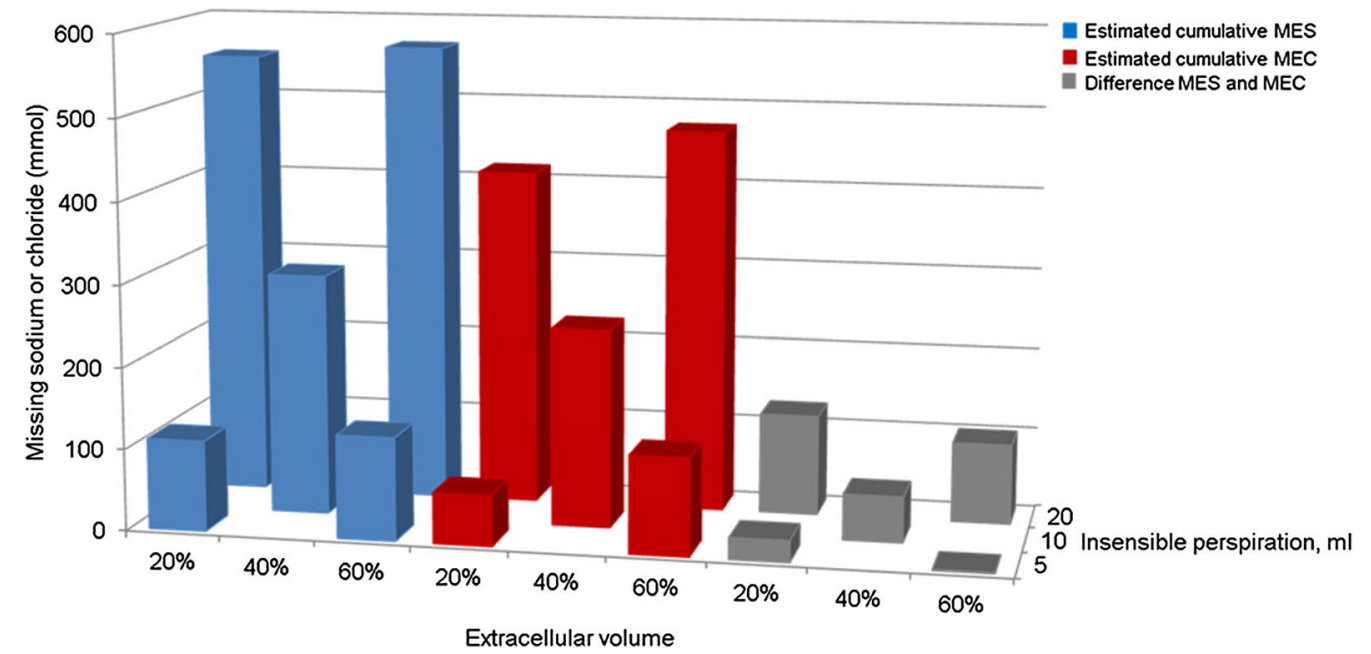

Fig. 3 Estimated cumulative MES and MEC according to different scenarios. Values are depicted as means. The calculated MES (blue), MEC (red) and their difference (light gray) on ICU day 4 according to the scenarios with different assumptions on perspiration and the size of the extracellular volume

$[2,3,20]$. Sodium changes in the tissues of ICU patients resulting from MES could be imaged via ${ }^{23} \mathrm{Na}$ MRI. To our knowledge, ${ }^{35} \mathrm{Cl}$ MRI has not yet been used to study MEC, but it is a promising and intriguing technique to identify the anatomical spaces where salt is stored [32, 33]. Importantly, this technique should be able to differentiate between the two main explanations for missing sodium and chloride: nonosmotic storage or intracellular uptake.

Our study has a number of limitations. Due to its retrospective design, we could not control for many variations in standard care. We had to make several assumptions, as, for example, for the insensible perspiration or the size of the ECV. However, we believe that the extreme scenarios on perspiration and ECV in our sensitivity analyses covered all realistic scenarios. We did not account for fecal losses, as we could not retrieve this information. Since we observed early postoperative patients, fecal production was absent or very low and, moreover, loss of sodium and chloride through the gut is usually very limited [34]. We did not measure weight changes as this is not routine procedure at our unit. Daily weight measurements could be added in the future to further validate our results.

On the relatively short term, differences in body weight measured in $\mathrm{kg}$ as measured in ICU patients will be less accurate than fluid balances measured in $\mathrm{mL}$. Therefore, we only used initial recorded weight to estimate the ECV. Fluid balances in critically ill patients often have a poor correlation with changes in body weight $[35,36]$. Especially cumulative fluid balance is prone to errors, as measuring errors get cumulated [36], which we accounted for in our error estimates. It must be noted that body weight measurement also has multiple possible errors, which could be the explanation of the lack of association between fluid balance and differences in body weight [36]. However, we believe that due to the short time this study covers and the meticulous recalculation of the fluid balance, including gastric retention, drain fluids and insensible perspiration, we have minimized errors as far as realistically possible.

Insensible perspiration remains very challenging to measure. As MES and MEC were most influenced by insensible perspiration, the lack of direct measurement of perspiration is an important limitation of our study. We tried, however, to maximize the chance to include the true value as much as possible with our five different scenarios. Direct measurement of (in)sensible perspiration would make estimated of MES and MEC more accurate (Fig. 3). Unfortunately, we are not aware of reliable tools to measure (in)sensible perspiration.

In this first observational balance study, we selected our patients based on complete balance data, which could have induced selection bias. The Androque-Madias [37] and Nguyen-Kurtz [38] formulas are frequently used when estimating the plasma sodium level after a saline infusion in dysnatremic ICU patients $[17,19]$. However, we choose not to use these formulas in our study, as they do not account for excretion of sodium or chloride or they use empirically derived constants which were not suitable for using in our model. However, predictions on the size of the ECV from both formulas fall within the four scenarios. 
In conclusion, our detailed sodium and chloride balances in ICU patients after cardiothoracic surgery suggest a loss of osmotically active sodium and chloride from the ECV. The estimates depend considerably on the scenarios used. Whether these ions are nonosmotically stored or transferred to the intracellular space needs further study.

\section{Additional file}

Additional file 1. Detailed information on constants and calculations and sex-specific model for MES and MEC.

\section{Abbreviations}

AKI: acute kidney injury; APACHE-IV: Acute Physiology and Chronic Health Evaluation-IV; ECV: extracellular volume; ICU: intensive care unit; ICV: intracellular volume; MEC: missing extracellular osmotically active chloride; MES: missing extracellular osmotically active sodium; MRI: magnetic resonance imaging; $\left[\mathrm{Na}^{+}\right]_{\text {first }}$ : plasma sodium concentration on day of measurement; $\left[\mathrm{Na}^{+}\right]_{\text {last }}$ : last plasma sodium concentration previous day; $\triangle \mathrm{Na}_{\text {obs: }}$ : observed change in estimated extracellular sodium; $\Delta \mathrm{Na}_{\text {exp }}$ : expected change in estimated extracellular sodium

\section{Authors' contributions}

LH collected, analyzed and interpreted the data and was the main writer of the manuscript. AOL and MZH made important intellectual contributions to the manuscript. MWN conceived and oversaw the collection, analysis and interpretation of the data and made important intellectual contributions to the manuscript. All authors read and approved the final manuscript.

\section{Author details}

${ }^{1}$ Department of Critical Care, University of Groningen, University Medical Center Groningen, Hanzeplein 1, 9700 RB Groningen, The Netherlands. ${ }^{2}$ Department of Anesthesiology, University of Groningen, University Medical Center Groningen, Groningen, The Netherlands.

\section{Acknowledgements}

We would like to thank Flip Baardman, Rients de Boer and André Fitze for meticulously recording patient data.

\section{Competing interests}

The authors declare that they have no competing interests.

\section{Availability of data and materials}

The datasets used and/or analyzed during the current study are available from the corresponding author on reasonable request.

\section{Consent for publication}

Not applicable.

\section{Ethics approval and consent to participate}

The study was approved by the medical ethics committee (IRB) of our institution (Medisch Ethische Toetsingscommissie, METc 2015.089). As a retrospective study of routinely collected and anonymized data, informed consent was not required by our IRB.

\section{Funding}

No funding was used in conducting this research.

\section{Publisher's Note}

Springer Nature remains neutral with regard to jurisdictional claims in published maps and institutional affiliations.
Received: 2 April 2018 Accepted: 3 October 2018

Published online: 11 October 2018

\section{References}

1. Titze J, Maillet A, Lang R, Gunga HC, Johannes B, Gauguelin-Koch G, et al. Long-term sodium balance in humans in a terrestrial space station simulation study. Am J Kidney Dis. 2002:40:508-16.

2. Titze J, Lang R, Ilies C, Schwind KH, Kirsch KA, Dietsch P, et al. Osmotically inactive skin $\mathrm{Na}^{+}$storage in rats. Am J Physiol Renal Physiol. 2003:285:F1108-17.

3. Linz P, Santoro D, Renz W, Rieger J, Ruehle A, Ruff J, et al. Skin sodium measured with 23Na MRI at 7.0 T. NMR Biomed. 2015;28:54-62.

4. Titze J, Shakibaei M, Schafflhuber M, Schulze-Tanzil G, Porst M, Schwind $\mathrm{KH}$, et al. Glycosaminoglycan polymerization may enable osmotically inactive $\mathrm{Na}^{+}$storage in the skin. Am J Physiol Heart Circ Physiol. 2004;287:H203-8.

5. Machnik A, Neuhoger W, Jantsch J, Dahlmann A, Tammela T, Machura K, et al. Macrophages regulate salt-dependent volume and blood pressure by a vascular endothelial growth factor-C-dependent buffering mechanism. Nat Med. 2009:15:545-52.

6. Wiig H, Schröder A, Neuhofer W, Jantsch J, Kopp C, Karlsen TV, et al. Immune cells control skin lymphatic electrolyte homeostasis and blood pressure. J Clin Invest. 2013;123:2803-15.

7. Benz K, Schlote J, Daniel C, Kopp C, Dahlmann A, Schröder A, Cordasic $\mathrm{N}$, et al. Mild salt-sensitive hypertension genetically determined low nephron number is associated with chloride but not sodium retention. Kidney Blood Press Res. 2018:43:1-11.

8. Hessels L, Oude Lansink A, Renes MH, van der Horst IC, Hoekstra M, Touw DJ, et al. Postoperative fluid retention after heart surgery is accompanied by a strongly positive sodium balance and a negative potassium balance. Physiol Rep. 2016:4:e12807.

9. Waite MD, Fuhrman SA, Badawi O, Zuckerman IH, Franey CS. Intensive care unit-acquired hypernatremia is an independent predictor of increased mortality and length of stay. J Crit Care. 2013;28:405-12.

10. Oude Lansink-Hartgring A, Hessels L, Weigel J, de Smet AMGA, Gommers D, Panday PVN, et al. Long-term changes in dysnatremia incidence in the ICU: a shift from hyponatremia to hypernatremia. Ann Intensive Care. 2016;6:22.

11. Shaw AD, Raghunathan K, Peyerl FW, Munson SH, Paluskiewicz SM, Schermer CR. Association between intravenous chloride load during resuscitation and in-hospital mortality among patients with SIRS. Intensive Care Med. 2014:40:1897-905.

12. Yunos NM, Bellomo R, Story D, Kellum J. Bench-to-bedside review: chloride in critical illness. Crit Care. 2010;14:226.

13. Kellum JA, Lameire N. Diagnosis, evaluation, and management of acute kidney injury: a KDIGO summary (part 1). Crit Care. 2013:17:204.

14. Cox P. Insensible water loss and its assessment in adult patients: a review. Acta Anaethesiol Scand. 1987;21:771-6.

15. Corcoran T, Rhodes JE, Clarke S, Myles PS, Ho KM. Perioperative fluid management strategies in major surgery: a stratified meta-analysis. Anaesth Analg. 2012;114:640-51

16. Guyton AC. Textbook of medical physiology. 11th ed. Philadelphia, PA: Saunders Elsevier; 2011. p. P285-P300.

17. Lindner G, Schwarz C, Kneidinger N, et al. Can we really predict the change in plasma sodium levels? An analysis of currently proposed formulae in hypernatraemic patients. Nephrol Dial Transplant. 2008;23:3501-8.

18. Nutrition facts label sodium FDA. https://www.accessdata.fda.gov/scrip ts/InteractiveNutritionFactsLabel/sodium.html. Accessed 15 Dec 2017.

19. Olde Engberink RH, Rorije NM, van den Born BJ, Vogt L. Quantification of nonosmotic sodium storage capacity following acute hypertonic saline infusion in healthy individuals. Kidney Int. 2017;91:738-45.

20. Kopp C, Linz P, Wachsmuth L, Dahlmann A, Horbach T, Schöfl C, et al. (23)Na magnetic resonance imaging of tissue sodium. Hypertension. 2012;59:167-72.

21. Kopp C, Linz P, Dahlmann A, Hammon M, Jantsch J, Müller DN, et al. 23Na magnetic resonance imaging-determined tissue sodium in healthy subjects and hypertensive patients. Hypertension. 2013;61:635-40. 
22. Schneider MP, Ralf U, Kopp C, Scheppach JB, Toncar S, Wanner C, et al. Skin sodium concentration correlates with left ventricular hypertrophy in CKD. J Am Soc Nephrol. 2017;28:1867-76.

23. Dahlmann A, Dorfelt K, Eicher F, Linz P, Kopp C, Mössinger I, et al. Magnetic resonance-determined sodium removal from tissue stores in hemodialysis patients. Kidney Int. 2015;87:434-41.

24. Hammon M, Grossmann S, Linz P, Kopp C, Dahlmann A, Garlichs C, et al. $23 \mathrm{Na}$ magnetic resonance imaging of the lower leg of acute heart failure patients during diuretic treatment. PLoS ONE. 2015;10:e0141336.

25. Van Ijzendoorn MCO, Buter H, Kingma WP, Navis GJ, Boerma EC. The development of intensive care unit acquired hypernatremia is not explained by sodium overload or water deficit: a retrospective cohort study on water balance and sodium handling. Crit Care Res Pract. 2016;2016:9571583

26. Zaferani A, Talsma DT, Yazdani S, Celie JW, Aikio M, Heljasvaara R. Basement membrane zone collagens XV and XVIII proteoglycans mediate leukocyte influx in renal ischemia/reperfusion. PLoS ONE. 2014;9:e106732.

27. Severs D, Hoorn EJ, Rookmaker MB. A critical appraisal of intravenous fluids: from the physiological basis to clinical evidence. Nephrol Dial Transplant. 2015:30:178-87.

28. Van Regenmortel N, Verbrugghe W, Roelant E, van den Wyngaert T, Jorens PG. Maintenance fluid therapy and fluid creep impose more significant fluid, sodium, and chloride burdens than resuscitation fluids in critically ill patients: a retrospective study in a tertiary mixed ICU population. Intensive Care Med. 2018;33:409-17.

29. Titze J, Krause H, Hecht H, Dietsch P, Rittweger J, Lang R, et al. Reduced osmotically inactive $\mathrm{Na}^{+}$storage capacity and hypertension in the Dahl model. Am J Physiol Renal Physiol. 2002;283:F134-41.
30. Dahlmann A, Kopp C, Linz P, Cavallaro A, Seuss H, Eckardt KU, Luft FC, et al. Quantitative assessment of muscle injury by (23)Na magnetic resonance imaging. Springerplus. 2016;5:661.

31. Kress JP, Hall JB. ICU-acquired weakness and recovery from critical illness. N Engl J Med. 2014;370:1626-35.

32. Nagel AM, Lehmann-Horn F, Weber MA, Jurkat-Rott K, Wolf MB, Radbruch A, et al. In vivo 35Cl MRI imaging in humans: a feasibility study. Radiol. 2014;274:585-95

33. Baier S, Kramer P, Grudzenski S, Fatar M, Kirsch S, Schad LR. Chloride and sodium chemical shift imaging during acute stroke in a rat model at 9.4 Tesla. MAGMA. 2014;274:71-9.

34. Heer M, Baisch F, Kropp J, Gerzer R, Drummer C. High dietary sodium chloride consumption may not induce body fluid retention in humans. Am J Physiol Renal Physiol. 2000;278:F585-95.

35. Schneider AG, Baldwin I, Freitag E, Glassford N, Bellomo R. Estimation of fluid status changes in critically ill patients: fluid balance chart or electronic bed weight? J Crit Care. 2012;27:745.e7-12.

36. Schneider AG, Thorpe C, Dellbridge K, Matalanis G, Bellomo R. Electronic bed weighing vs daily fluid balance changes after cardiac surgery. J Crit Care. 2013:28:1113e1-5.

37. Androgué HJ, Madias NE. Aiding fluid description for the dysnatremias. Intensive Care Med. 1997;23:309-16.

38. Nguyen MK, Kurtz I. Analysis of current formulas used for treatment of the dysnatremias. Clin Exp Nephrol. 2004:8:12-6.

\section{Submit your manuscript to a SpringerOpen ${ }^{\circ}$ journal and benefit from:}

- Convenient online submission

- Rigorous peer review

- Open access: articles freely available online

- High visibility within the field

- Retaining the copyright to your article

Submit your next manuscript at $\boldsymbol{\nabla}$ springeropen.com 